\title{
Depression and Mental Health Reference to Gender of College Students
}

\author{
Prof. (Dr.) Jayendra A. Jarsaniya ${ }^{1}$
}

\begin{abstract}
:
The present study is intended was to find out the depression and mental health of college students. The variables included for the study apart from depression and mental health is gender of college students. The study was conducted on a sample of 120 students ( 60 boy students, 60 girl students) simple randomly selected from the various colleges at Rajkot city. Standardized questionnaire developed by Dr. D. J. Bhatt for mental health and for depression inventory developed by Beck depression inventory (Guajarati adaption) was used in this study. The data was analyzed to examine the influence of individual factors on depression and mental health dependent variables. ' $t$ ' test was used for calculation for independent variable of gender and the Karl-person ' $r$ ' method used to check the correlation between depression and mental health. The results shows that there was a significant mean difference in relation to gender and result of co-relation between depression and mental health reveals $\mathbf{- 0 . 4 1 8}$ negative correlation of college students.
\end{abstract}

Keywords: Depression; Mental Health; college students.

Menninger (1945) defined mental health as the adjustment of human beings to the world and to each other with a maximum of effectiveness and happiness. It is the ability to maintain an even temper, an alert intelligence, socially considerate behavior and a happy disposition. Mental health can be described as absence of symptoms of maladjustment, be they mild or severe. Mentally healthy person is free from all types of maladjustment (Klein, 1956).

Jahoda (1958) has said that aspects of attitudes toward self, growth and development, selfactualization, integration of personality and mastery of the environment must be considered in judging whether a person is mentally healthy or not. Mental health is how we think, feel and act as we cope with life. It also helps determine how we handle stress, relate to others and make choices. Like physical health, mental health is important at every stage of life, from childhood and adolescence through adulthood.

${ }^{1}$ Associate Professor, Smt. K. S. N. Kansagara Mahila College, Rajkot-Saurashtra University.

(C) 2015 I A. Jarsaniya; licensee IJIP. This is an Open Access Research distributed under the terms of the Creative Commons Attribution License (http://creativecommons.org/licenses/by/2.0), which permits unrestricted use, distribution, and reproduction in any Medium, provided the original work is properly cited. 
The concept of Mental Health as well as illness is not a new one. Its roots are to be found in the early prehistory of man. Clinical Psychologist as well as educationists has started giving proper attention to the study of mental health \& Mental illness. However, in India. It is relatively a new field of study. Mental health incorporates the concepts of personality characteristics and behavior all in one. In today's fact paced, technological world, there are often a variety of quick treatment for physical ailments, but not so for mental once. If anything treatment for mental health takes time and patience for maximum effectiveness. In order to understand exactly what is meant by "Mental health." We need to first define what the overarching concept of 'health' means.

Scientists in the past defined health simply as "an absence of disease or illness". However, in 1948. When the world Health organization (WHO) was founded the following definition of Health was established: "A complete state of physical Mental and social well-being and not merely the absence of disease or infirmity." Looking at this definition, we realize that individuals can at once be relatively healthy in some aspects of life, but unhealthy in others. Thus, being healthy is not an "all-or-nothing" principle. It is easy to assess physical health by taking health status measurements of the body.

Blood pressure, temperature, and cholesterol levels are all precise means by which we can tell if the physical components of the body are healthy, However Mental and Social components of health are much more challenging to assess. Though is and perception of internal states are subjective and difficult to quantity. What then is mental health?

Mental health, as defined by the surgeon General's report on Mental Health, refers to the successful performance of mental function resulting in productive activities, fulfilling relationship with other people and the ability to adopt to change and cope with adversity on the other and of the continuum is mental illness, which refers to all mental disorders." So, mental Health is attitudinal concept towards us and others. It also presents a humanistic approach towards the understanding and assessment of the self, positive feeling attitude towards self and others.

Depression is more common among women than among men. Biological, life cycle, hormonal, and psychosocial factors that women experience may be linked to women's higher depression rate. Researchers have shown that hormones directly affect the brain chemistry that controls emotions and mood. For example, women are especially vulnerable to developing postpartum depression after giving birth, when hormonal and physical changes and the new responsibility of caring for a newborn can be overwhelming.

Some women may also have a severe form of premenstrual syndrome (PMS) called premenstrual dysphoric disorder (PMDD). PMDD is associated with the hormonal changes that typically occur around ovulation and before menstruation begins. During the transition into menopause, some women experience an increased risk for depression. In addition, osteoporosis-bone thinning or loss-may be associated with depression. Scientists are 
exploring all of these potential connections and how the cyclical rise and fall of estrogen and other hormones may affect a woman's brain chemistry. An old person begins to feel that even his children do not look upon him with that degree of respect, which he used to get some years earlier. The old persons feel neglected and humiliated. This may lead to the development of psychology of shunning the company of others.

\section{REVIEW OF LITERATURE:}

Sirohi (2002) conducted the study on the effect of religion on mental health. The sample consisted of 250 XI standard boys covering three religions (i.e) Hindu $(n=105)$, Christian $(n=$ 80) and Muslim ( $n=80)$. Sirohi Mental Health Questionnaire developed by the author was used for assessing the mental health of adolescents. He reported that Christian had significantly poor mental health when compared with Hindu and Muslim boys.

Vasuki and Charumathy (2004) compared the sibling rivalry with achievement motivation, frustration, mental health and self conflict of adolescents on a sample of 60 girls and 60 boys of age 15-18 years. Mental health was assessed by mental health inventory developed by Jagdish and Srivastava (1983). Rivalry resulted in inferior level of achievement motivation and poor mental health. Greater extent of sibling rivalry also leads the adolescents to become more frustrated.

\section{OBJECTIVES:}

To check the correlation between mental and Stress.

1. To find out the significant difference of depression of college students in relation to their gender.

2. To find out the significant difference of mental health of college students in relation to their gender.

3. To find out the co-relation between depression and mental health.

\section{HYPOTHESIS:}

1. There is no significant mean difference between the mean of depression of college students in relation to their gender.

2. There is no significant mean difference between the mean of mental health of college students in relation to their gender.

3. There is no co-relation between depression and mental health.

\section{VARIABLES:}

A. Independent variables: Gender

1. Boys Students 


\section{Girls Students}

B. Dependent variables:

1. Depression of Students

2. Mental Health of Students

\section{METHOD:}

\section{Sample:}

In the present study sample was selected simple random methods. The present study was taken as a sample 60 boys students who were studying in under Graduate (Arts, Commerce and Science) college also 60 girls students who were studying in under Graduate (Arts, Commerce and Science) college. Total 120 samples were selected in this study. College students were taken in difference residence area at Rajkot City. Approximately 145 samples were selected in category for the research study. After disposing off incomplete and nuclear details, a total of 120 samples were selected as primary planning.

Tools:

\section{Back Depression Inventory (BDI):}

Back Depression Inventory was developed by Beck. consist of 21 items assess the presence and intensity of depressive symptomatology and the items were scored from 0 to 3. This inventory has test-retest reliability coefficient ranging from 0.74 to 0.83 on different time intervals and positively correlated with Hamilton depression rating scale with a person of 0.71. Reliability and validity of Gujarati adaption in Sardar Patel University was 0.80 and 0.65 .

\section{Mental Health Scale:}

The Mental Health Scale was developed and revised by Dr. D. J. Bhatt \& shilpa (1997). The scale consisted of 40 items, each was to be rated on three point scale. Getting total score minimum 0 to maximum 120 in this scale. The reliability of this scale is 0.94 and validity is 0.63 established by the author.

\section{Procedure:}

The main aim of the present research was to a study of depression and mental health in college students. For these total 120 studding in college students were taken as a sample. Here to measure depression, back depression inventory and For Mental Health Dr. D. J. Bhatt \& shilpa inventory was used. To measure the Difference between groups' by t-test and the Karl-Pearson ' $r$ ' method was used to check the correlation. Independent Variable 
gender (Male Students / Female Students) and Dependent variable 1, Depression 2, Mental Health.

\section{RESULT AND DISCUSSION:}

Table-1

Mean, SD and 't' value of Depression score of boys and girls students.

\begin{tabular}{|l|l|l|l|l|l|}
\hline Group & N & Mean & SD & ' 't' Value & Sig. Level \\
\hline Boys Students & 60 & 34.17 & 6.12 & & \\
\hline Girls Students & 60 & 32.86 & 5.38 & & NS \\
\hline
\end{tabular}

Seen from table no1 that ' $t$ ' value of 1.25 is not significant at 0.05 level. This means that the two groups under the study differ not significantly in relation to depression. The mean score of boy students group is 14.17 as against the mean score of 12.86 of the girls students group. It should be remembered here that, according to scoring pattern, higher score indicate high depression. Thus from the result it could be said that the boys students is having little more depression than girl students group. The hypothesis that "There is no significant mean difference between the mean of depression of college students in relation to their gender." is accepted.

Table-2

Mean, SD and ' $t$ ' value of Mental Health score of boys and girls students.

\begin{tabular}{|l|l|l|l|l|l|}
\hline Group & N & Mean & SD & 't' Value & Sig. Level \\
\hline Boys Students & 60 & 75.42 & 9.87 & & \\
\hline Girls Students & 60 & 79.21 & 10.04 & & 0.05 \\
\hline
\end{tabular}

Seen from table no 2 that ' $t$ ' value of 2.09 is significant at 0.05 level. This means that the two groups under study differ significantly in relation to mental health. The mean score of boy students group is 75.42 as against the mean score of 79.21 of girl students group. It should be remembered that, according to scoring pattern, higher score indicate good mental health. Thus from the result it could be said that the girl students group is having good mental health than boy students group. The hypothesis that "There is no significant mean difference between the mean of mental health of college students in relation to their gender." is rejected. 
Table no. 3

Correlation between depression and Mental Health of Students

\begin{tabular}{|l|l|l|l|l|}
\hline Dependent Variable & N & Mean & r-Value & Sig. Level \\
\hline Depression & 60 & 33.52 & & \\
\hline Mental Health & 60 & 77.31 & $-0.418^{* *}$ & 0.01 \\
\hline
\end{tabular}

**. Correlation is significant at the 0.01 level

Seen from table no. 3 the results obtain that negative correlation between depression and Mental health boys and girls students. The $\mathbf{- 0 . 4 1 8}$ negative correlation between depression and Mental health. So we can say that third hypothesis was not accepted. It means as the depression increases the mental health decreases and depression decreases the mental health increases.

\section{CONCLUSIONS:}

1. There was no significant mean difference in Depression relation to boys and girls students.

2. There was a significant mean difference in Mental health relation to boys and girls students.

3. There were $\mathbf{- 0 . 4 1 8}$ negative correlations are seen between depression and mental health among boys and girls students.

\section{REFERENCES:}

1. Beck AT, Steer RA, Brown G (1996); The beck depression inventory-Second Edition. Manual for the Beck Depression Inventory-II. San Antonio, TX: Psychological Corporation.

2. Beck, C. (2001); Revision of the Postpartum Depression Predictors Inventory. Journal of Obstetrics \& Gyneacology NN, 31(4), 394-402.

3. Bhatt, D. J. \& Gida, Geeta R. (1992); The Mental Health Hygiene Invertory (M.H.I.). Construction and Standardization Unpublished M. Phil Dissertation Theses, Dept. of Psychology, Saurashtra University, ajkot 24-29.

4. Brummelte, S., Pawluski, J. L. \& Galea, L. A. (2006); High post-partum levels of corticostrone given to dams influence postnatal hippocampal cell proliferation and behavior of offspring: A model of post-partum stress and possible depression. Hormones and Behavior, 50, 370-382. 
5. $\quad$ Dave C.B and Sons (1986); Statistical psychology, Viral Publishers, Ahmedabad.

6. Dennis, C.-L. and Ross, L. E. (2006); Women's perceptions of partner support and conflict in the development of postpartum depressive symptoms. Journal of Advanced Nursing, 56(6), 588-599.

7. Kaplan HI, Shadock BJ (1996); Concise Text book of clinical psychology. Lippiocott Williams and Wilkins, Philadelphia, USA.

8. M.Subramanian and Dr. S.Krishnamurthy 'A Study of mental health of post graduate commerce students and their achievement in commerce subject, 'Indian Streams Research Journal (April ; 2012)

9. Mohanth N, Begum FA (2011); Geriateric depression, loneliness and psychological wellbeing: Roll of age and gender. Indian Journal of Psychology and Mental Health 5: 53-61.

10. Srivastava, S. K., Prasad, Deepesh chand and kumar, vipin, (1999); 'A study of mental health of hindi and English medium students'. J. Edu. Res. Extn. , 36 (3) : 23-28.

11. Srividhya V. (2011)'Mental health and adjustment problem of students of navodhaya central and state schools', Dharvad university.

12. Weissman MM, Bland RC, Canino GJ, Faravelli C, Greenwald S, et al. (1996) Crossnational epidemiology of major depression and bipolar disorder. JAMA 276: 293-299. 